\title{
Hispanismes
}

Revue de la Société des Hispanistes Français

16 | 2020

Langues en contact avec l'espagnol et défis sociétaux

\section{Lenguas en contacto con el español y desafíos sociales. Presentación}

Langues en contact avec l'espagnol et défis sociétaux. Présentation

Languages in contact with Spanish and societal challenges. Presentation

\section{Alicia Fernández García y Marta López Izquierdo}

\section{(2) OpenEdition}

Journals

\section{Edición electrónica}

URL: https://journals.openedition.org/hispanismes/733

DOI: 10.4000/hispanismes.733

ISSN: 2270-0765

Editor

Société des Hispanistes Français

\section{Referencia electrónica}

Alicia Fernández García y Marta López Izquierdo, «Lenguas en contacto con el español y desafíos sociales. Presentación», HispanismeS [En línea], 16 | 2020, Publicado el 01 diciembre 2020, consultado el 31 agosto 2021. URL: http://journals.openedition.org/hispanismes/733 ; DOI: https://doi.org/ 10.4000/hispanismes.733

Este documento fue generado automáticamente el 31 agosto 2021.

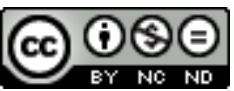

Les contenus de cette revue sont mis à disposition selon les termes de la Licence Creative Commons Attribution - Pas d'Utilisation Commerciale - Pas de Modification 4.0 International. 


\title{
Lenguas en contacto con el español y desafíos sociales. Presentación
}

\author{
Langues en contact avec l'espagnol et défis sociétaux. Présentation \\ Languages in contact with Spanish and societal challenges. Presentation
}

Alicia Fernández García y Marta López Izquierdo

1 El estudio del contacto de lenguas, que nace en la lingüística contemporánea a mediados del siglo pasado con Uriel Weinreich ${ }^{1}$, se sitúa en la encrucijada de la lingüística con otras disciplinas, principalmente la sociología, la psicología, las ciencias políticas y la antropología. Esta perspectiva va de la mano con la idea de que las situaciones de bilingüismo o plurilingüismo no pueden explicarse desde un punto de vista descriptivo exclusivamente sistémico, sino que deben abordarse desde la interacción compleja de factores a la vez internos y externos. Por ello, los fenómenos de cambio lingüístico, cambio de lengua, préstamos, interferencias, mezclas y alternancias códicas... se estudian considerando el papel de factores como la comunidad lingüística, las fronteras lingüísticas, las situaciones de migración, y muchos otros. Situándonos dentro de este marco interdisciplinar, ofrecemos un conjunto de trabajos que, desde perspectivas lingüísticas, sociolingüísticas, sociológicas o políticas, abordan diversas situaciones de contacto en España y fuera de España y de los conflictos que se derivan de ellas.

2 Es necesario recordar que las situaciones de contacto lingüístico entre dos o más lenguas dentro de una entidad nacional son mayoritarias en el mundo. El multilingüismo es por consiguiente la situación más normal en el planeta. A pesar de que la mente humana está capacitada para el aprendizaje simultáneo de varios códigos lingüísticos desde la infancia ${ }^{2}$ y de las ventajas cognitivas que se asocian con el cerebro bilingüe $^{3}$, la coexistencia de dos o más lenguas en un mismo territorio está frecuentemente asociada a una situación de conflicto lingüístico ${ }^{4}$. Ello es así, principalmente, porque en estas situaciones, una comunidad dominante (desde el punto de vista político, económico o cultural) se impone, con sus estructuras, su cultura y su lengua, sobre otra comunidad más débil, la cual puede ofrecer mayor o menor resistencia en este proceso. 
3 La noción de diglosia que Ferguson acuña en $1959^{5}$ para describir situaciones lingüísticas en que coexisten dos variedades de una misma lengua, con un reparto de funciones diferenciadas, será ampliada por Fishman ${ }^{6}$ para aplicarla a situaciones de bilingüismo (dos lenguas diferentes) con una distribución de tipo diglósico (lengua $\mathrm{H}$ (high) o lengua de prestigio / lengua L (low) o lengua familiar, de menor prestigio). En estos casos, escribe este autor, las dos lenguas son complementarias y no hay lugar para el conflicto lingüístico:

Both [...] were fully accepted as culturally legitimate and complementary (i.e. nonconflictual) and indeed, little if any conflict between them was possible in view of the functional separation between them ${ }^{7}$.

4 Fishman considera igualmente que las dos lenguas en contacto podrán mantenerse dentro de una comunidad solo si se mantiene un funcionamiento diglósico entre ellas, es decir, si a cada una se le reservan determinadas funciones sociales, que no están en competición con las de la otra. Cuando ambas lenguas comienzan a disputarse el mismo terreno funcional, comienza igualmente el desplazamiento de la una por la otra. Ha de notarse que esta sustitución no se concibe en Fishman como una situación de conflicto, sino simplemente de resolución natural de una redundancia: si los dos códigos sirven para las mismas cosas, es natural que uno de ellos acabe sustituyendo al otro. Y naturalmente, es la lengua o variedad que se asocia con el mayor prestigio la que terminará ocupando todo el espacio ${ }^{8}$.

5 En la sociología del lenguaje se han enfrentado el «modelo armónico», que vendría representado por la visión de Fishman que acabamos de mencionar, y el «modelo del conflicto» ${ }^{9}$. En el modelo armónico, las dos lenguas en contacto tienen una relación de complementariedad y ocupan cada una su propia esfera de actividades ${ }^{10}$. Como hace notar Williams ${ }^{11}$, este esquema sigue una visión evolucionista, según la cual todo bilingüismo se concibe como una fase de transición hacia un monolingüismo. Según Nelde, no todas las situaciones de contacto conllevan necesariamente tensiones o conflictos, y es posible encontrar ejemplos de convivencia pacífica entre comunidades $^{12}$. Sin embargo, las tensiones aparecen siempre que una diferencia entre grupos puede engendrar desigualdad de estatus. Para el «modelo del conflicto», las relaciones entre una lengua dominante y una lengua dominada no son de complementariedad sino de exclusión de una de ellas, la lengua dominada, de los ámbitos de prestigio de una sociedad (administración, decisiones políticas, educación, etc.) ${ }^{13}$. El grupo desfavorecido se encuentra entonces ante la disyuntiva de renunciar a sus ambiciones de ascenso social, asimilarse o resistir. En el mundo contemporáneo, es frecuente la resistencia política de grupos minoritarios homogéneos con fuertes tradiciones históricas, culturales o religiosas compartidas. El conflicto se intensifica en aquellas situaciones en que el grupo minoritario ve bloqueado su ascenso social si no lleva a cabo una asimilación.

6 Es importante destacar que, en estos casos, el conflicto lingüístico no se origina en las lenguas, sino en las relaciones de desigualdad política, social, económica... que se asocian con las lenguas en juego. Puede hablarse así de un conflicto lingüístico «de superficie», que oculta un conflicto más profundo de naturaleza diferente ${ }^{14}$. En este sentido, el conflicto lingüístico es en realidad un conflicto entre hablantes de distintas lenguas.

7 Por otro lado, se ha afirmado que el bilingüismo y la diglosia no responden a un desarrollo histórico natural, sino que son el resultado de la dominación lingüística o 
incluso la coacción lingüística ${ }^{15}$. Así, el origen de los Estados-Nación europeos entre los siglos XVI y XIX condujo a la superposición en un mismo territorio de una lengua dominante o nacional y una lengua dominada o regional, que en muchos casos entra en peligro de desaparición. Este mismo patrón se exporta a nuevos continentes con la expansión colonial mundial entre los siglos XIX y XX.

Cabe considerar, asimismo, dentro de esta perspectiva histórica, la aparición de contactos lingüísticos como consecuencia de movimientos migratorios y exilios, un fenómeno recurrente que lleva también a situaciones donde la lengua de las comunidades migrantes se encuentra en una posición marginal respecto a la lengua o las lenguas del país de acogida.

El conflicto lingüístico que se estudia en las diversas situaciones de contacto no debe entenderse sin embargo solo como un fenómeno negativo, puesto que posibilita la aparición de cambios y soluciones que desembocan en mejoras para la situación de los grupos más vulnerables. Los ejemplos de Canadá y Bélgica, estudiados por Nelde, muestran la eficacia de medidas nacidas a raíz de conflictos lingüísticos, entre ellas, la base territorial de las lenguas en contacto (determinadas regiones utilizan una lengua prioritaria en ámbitos restringidos: administración, educación) o la protección de los grupos que se encuentran en situación minoritaria para favorecer su desarrollo. Este tipo de medidas podría contribuir a la reducción de grupos con posiciones ideológicas marcadas y al descenso de la carga emocional asociada.

\section{Conflictos sociales, políticos y culturales en situaciones de contacto}

10 Este número especial presta especial interés a los desafíos sociales a los que se enfrentan las comunidades en las que existe una práctica bilingüe o plurilingüe significativa. En este sentido, buena parte de las contribuciones presentadas proponen considerar determinadas zonas periféricas del territorio español como el País Vasco o Cataluña, así como las ciudades autónomas de Ceuta y Melilla y determinados territorios peninsulares como Gibraltar, en tanto que lugares privilegiados para el estudio de los contactos sociales y para un mejor conocimiento de los desafíos de la construcción social en territorios bilingües o multilingües. En dichas contribuciones, el territorio posee así el papel de filtro y ejerce la función de «contacto». También se concibe como garante de la coherencia entre estos y aquellos, como un común que debe ser transmitido por dinámicas que permitan, por un lado, la apropiación social en estos territorios plurilingües y multiculturales, y por el otro, el funcionamiento de las interculturalidades sociales ${ }^{16}$. Es dentro de estos territorios " d'entre-deux $»^{17}$ marcados por lógicas de convivencia y conflicto $^{18}$ donde se construye la interculturalidad, cuya puesta en práctica se hace a través del cuestionamiento de las relaciones pasadas y la apertura a otros modelos de sociedad ${ }^{19}$.

11 La constatación de una pluralidad social, cultural y lingüística nos lleva a reflexionar sobre el vínculo social, sus formas y sus rupturas, pero también sobre el lugar de la diferencia, una diferencia percibida positivamente y no como una fuente de problemas o un ataque a la identidad a menudo concebida en singular. Y si el credo según el cual «ser es ser diferente» es ampliamente compartido ${ }^{20}$, buena parte de los casos de estudio propuestos en este número especial muestra cómo este derecho a la diferencia no es tan obvio como a simple vista parece. Una diferencia que, si bien es cierto que en 
los enclaves españoles de Ceuta y Melilla, en Gibraltar e incluso en el País Vasco o Cataluña se tolera, aunque con distinta intensidad, parece conllevar un riesgo de marginación y exclusión en la medida en que el otro se convierte a menudo en simplemente el otro, es decir, «aquel que al no tener nada parecido queda excluido de la convivialidad que nos une» ${ }^{21}$. El gran reto en estos territorios multiculturales y plurilingües estudiados en las contribuciones de Alicia Fernández, Mathieu Petithomme y Alexandra Novosseloff será lograr aceptar que la unión pierde su sentido y se agota si no se revitaliza en la diversidad aceptada y asumida ${ }^{22}$.

\section{Contactos y conflictos lingüísticos en el ámbito hispánico}

Las situaciones de conflicto son muy variadas, en función de las constelaciones políticas, históricas, económicas y culturales de cada territorio en que se produce el contacto entre dos o más lenguas. Valga citar situaciones tan diferentes como la del occitano o el bretón en contacto con el francés en Francia, el francés y el inglés en Quebec, el galés o el hindi en contacto con el inglés en Gran Bretaña o la India, del español y el inglés en EEUU o del portugués, francés o inglés en las antiguas colonias de África. En cada una de ellas, las comunidades de habla minoritaria o dominada, así como sus individuos, pueden seguir estrategias diferentes a la hora de mantener o abandonar la lengua vernácula, con multitud de posiciones intermedias entre ambos polos, desde el compromiso hasta la resistencia activa. El nivel de la autoestima que determinado grupo posee de su propia lengua y por consiguiente del prestigio a ella asociado y de su reivindicación, es fundamental a la hora de entender la promoción de una lengua dominada frente a la lengua dominante.

En el ámbito hispánico, las situaciones de contacto lingüístico son muy numerosas, desde los países de lengua oficial española en América o España, como en aquellos lugares que cuentan o han contado con una presencia importante de comunidades migrantes hispanohablantes. Consecuentemente, también serán numerosas y diversas las formas de convivencia que se establecen entre las lenguas y los grupos de hablantes de esas regiones. Para ceñirnos al caso español, la situación de contacto lingüístico (y por ende, de conflicto al menos potencial) se extiende a los territorios no monolingües de la nación, es decir aquellos en que se habla, además del español, el gallego, el vasco, el catalán o valenciano, y otras variedades lingüísticas de menos extensión institucional conocidas como aranés, navarro-aragonés, astur-leonés. La relación entre el español y estas otras lenguas del territorio español no sigue el patrón de otros países europeos, según sostiene López García:

ni el español es la «lengua nacional», como puedan serlo el francés o el italiano en sus respectivos países, ni el catalán, el gallego o el vasco son «lenguas regionales», según sucede con el corso, el veneciano, el bretón o, paradójicamente, con estos mismos catalán y vasco al norte de los Pirineos. La historia moderna de España ha demostrado que las tensiones territoriales son mucho más intensas que en aquellos otros países y que, más pronto o más tarde, acaban reclamando un sustrato lingüístico legitimador ${ }^{23}$.

14 Este mismo autor considera que España, más que un país plurilingüe, sería un país multilingüe, esto es un país en el que se hablan varias lenguas, pero en el que los ciudadanos no se esfuerzan por manejar más que la suya ${ }^{24}$. 
Por supuesto tal afirmación puede resultar de una generalización excesiva, pero no deja de sorprender que la enseñanza de las lenguas autonómicas solo se proponga en el currículo escolar de las autonomías propias, y que no se pueda estudiar el catalán, el vasco o el gallego en las escuelas, al menos como opción, fuera de los territorios tradicionalmente vinculados a estas lenguas. Por otra parte, las políticas lingüísticas que se han implantado progresivamente en las autonomías con población bilingüe han perseguido el ascenso de la lengua vehicular, buscando corregir una situación que se considera históricamente favorable para el español. Así, en Cataluña, se promueve al catalán como lengua vehicular única de la enseñanza ${ }^{25}$ y como lengua preferente en la administración pública, los medios de comunicación, las empresas públicas y privadas o la publicidad ${ }^{26}$. Políticas similares han buscado favorecer el uso del euskera en el País Vasco, gracias a las cuales la lengua vasca ha entrado en ámbitos institucionales y educativos que nunca antes había conocido en su historia ${ }^{27}$. La Lei de Normalización Lingüística gallega de 1983 y las medidas posteriores adoptadas en esta zona se desmarcan por la adopción de una política de normalización de «baixa intensidade», que se justifica por el deseo de evitar los conflictos:

a xestión política lingüística no noso país formulouse desde unha concepción arriba-abaixo caracterizada polo seu perfil extensivo 監co que isto comporta de feble acción institucional e apelación au voluntarismo dos axentes sociais閭 e pola evitación dos conflitos ${ }^{28}$.

16 Ha de considerarse además que las tensiones en torno al uso de las lenguas históricas hispánicas no se circunscriben a los territorios bilingües, sino que en las últimas décadas han saltado a la escena nacional y se han convertido en un elemento de disensión para el conjunto de la sociedad española, así como en un tema de debate desde todas las tribunas, ya sean estas académicas, políticas, periodísticas o simplemente ciudadanas. Han servido asimismo de argumento electoral para la política no solo autonómica sino también nacional, pues en la «cuestión lingüística» se han cristalizado los enfrentamientos entre los partidos nacionalistas «españolistas» y los que reclaman la auto-determinación para las regiones autónomas (esencialmente País Vasco y Cataluña).

Uno de los puntos que motiva mayor tensión se sustenta en la imagen del bilingüismo como una rivalidad entre lenguas: el uso de la una es visto como una pérdida para la otra, algo que se sostiene en la imagen evolucionista de Fishman ya mencionada, para quien el bilingüismo es una etapa transicional hacia el monolingüismo ${ }^{29}$. Esta visión domina en muchos estudios lingüísticos, que advierten sobre los peligros de una política que favorezca en demasía la lengua vernácula o por el contrario no lo haga. Así, López García ${ }^{30}$ se refiere a las políticas de normalización lingüística en Cataluña como «el intento, cada vez más indisimulado, de erradicar el español de dichas comunidades»; por su lado, Ferrando y Nicolàs ${ }^{31}$ afirman acerca de la situación del catalán en España, Francia e Italia, países donde existen comunidades catalanohablantes históricas:

hem constatat que el català, tot i els avanços sectorials, es manté en una situació diglòssica clara. $O$ per dir-ho en uns altres termes, és [...] una llengua residual que ha estat substituïda o es troba en curs de substitució per les llengües de l'estat: l'espanyol, el francès i l'italià [...].

De manera más militante y en la línea de Ninyoles, el grupo Koiné32 declara en su manifiesto de 2016: 
Denunciem la ideologia política de l'anomeant «bilingüisme», que s'ha anat inoculant des de les esferes de poder a tota la població catalana d'ençà del 1978 per justificar el règim jurídic establert per la Constitució i l'Estatut d'autonomia fent creure que la coexistència de dues llengües a Catalunya, totes dues amb un suposat mateix estatus d'oficialitat $\mathrm{i}$ igualtat de drets, és un fet natural, positiu, enriquidor i democràtic. En realitat, aquesta ideologia bilingüista no és res més que una forma d'encobrir i legitimar la subordinació d'una llengua a l'altra i el consegüent procés de substitució lingüística que pateix la societat catalana ${ }^{33}$. estos territorios, el peligro de desaparición o incluso de retroceso está lejos de confirmarse para la lengua dominante, aunque tampoco se observa un peligro inminente para las lenguas dominadas (gráfico 1). La tendencia global positiva de las cifras que se reproducen aquí debe ser sin embargo cuidadosamente examinada, ya que puede ocultar procesos recesivos en cuanto al uso mayoritario de una $u$ otra lengua en cada territorio, algo que analizan varios de los trabajos que recogemos en este volumen.

Gráfico 1. Evolución de las competencias lingüísticas en euskera, catalán y gallego.

\begin{tabular}{|l|l|l|}
\hline Vascohablantes $^{37}$ & Catalanohablantes $^{38}$ & Gallegohablantes $^{39}$ \\
\hline $1991: 24,1 \%$ & $2003: 60,2 \%$ & $1992: 86 \%$ \\
\hline $2016: 33,9 \%$ & $2018: 64,7 \%$ & $2018: 88 \%$ \\
\hline
\end{tabular}

El principal motivo de retroceso que amenaza a estas lenguas en el futuro probablemente no sea su convivencia tradicional, más o menos conflictiva, con la lengua española, sino los procesos de globalización y las sociedades multiculturales que esta engendra, las cuales conllevan una reconfiguración de los usos lingüísticos, especialmente en los centros urbanos, como analiza Mercè Pujol en su contribución a este volumen. 

estos enclaves y otros territorios multilingües de España. Los autores se plantean las preguntas siguientes: ¿Cuáles son las voluntades, representaciones y prácticas colectivas puestas en marcha por los habitantes del País Vasco, de Cataluña, de Gibraltar y también de las ciudades fronterizas de Ceuta y Melilla para garantizar el vivir juntos? ¿Cuál es la aceptación y el lugar de la diferencia en estas sociedades multiculturales y plurilingües? Partiendo de la premisa según la cual el lenguaje juega un papel central en lo que Castoriadis llamó la «institución imaginaria de la sociedad» ${ }^{40}$ y también en las representaciones sociales del territorio, los artículos de Mathieu Petithomme, Alicia Fernández y Alexandra Novosseloff hacen hincapié en el proceso de apropiación social en territorios multiculturales y plurilingües, y en las lógicas de construcción de la interculturalidad. En este sentido, la contribución de Alicia Fernández García explora la complejidad y ambivalencia de las relaciones sociales en Ceuta y Melilla. Dos enclaves originales en virtud de su ubicación (ciudades-frontera euroafricanas ${ }^{41}$ ) y dos ciudades de culturas debido a la mezcla de poblaciones. En su artículo, se analiza la situación social y lingüística de estas dos ciudades enclave situadas en el norte de África, muy poco estudiadas, a menudo olvidadas y poco conocidas por los españoles peninsulares. Del mismo modo, la autora se interesa por la naturaleza de la convivencia social en estos territorios fronterizos, por su impacto en las identidades de los habitantes, así como por los modos de identificación en las sociedades de estas dos ciudades cuya soberanía sigue siendo contestada. Por último, la investigadora también analiza los retos sociales a los que se enfrentan las distintas comunidades y/o colectivos que viven en estos enclaves en donde existe una importante práctica bilingüe o incluso plurilingüe. sobre Ceuta y Melilla al mismo tiempo que se interesa por otra ciudad enclave del Mediterráneo como es el peñón de Gibraltar. Bajo una mirada casi periodística enriquecida gracias a un importante dispositivo etnográfico, la autora estudia las condiciones de vida de sus habitantes, sus recursos económicos, sus particularidades políticas y administrativas e incluso sus problemáticas, a la vez que nos hace descubrir las contradicciones de las que se alimentan estos tres territorios en la encrucijada. Enclaves escrutados en cuanto legados históricos de un pasado a menudo defensivo, codiciados y preservados debido a su ubicación geográfica estratégica, las ciudades de Melilla, Ceuta y Gibraltar son, en efecto, pasajes privilegiados e incluso ineludibles entre Europa y África, que se han convertido en verdaderos pulmones económicos regionales.

Pero, ¿qué futuro les espera a estas ciudades enclave? Con esta cuestión Alexandra Novosseloff abre el debate y nos revela el estado de alerta latente en el que parecen vivir los habitantes de estos territorios-enclave en el Mediterráneo debido a las pretensiones soberanistas de sus respectivos vecinos, Marruecos con respecto a Ceuta y Melilla, y España en el caso de Gibraltar. Dos hinterlands que quisieran recuperar estas 
ciudades, aunque realmente poco les han pertenecido. Estas tres ciudades fronterizas están situadas geográficamente en continentes a los que en realidad no pertenecen, enclavadas en territorios que las acosan y abruman, pero a los que aún logran resistir. Resistir, este parece ser el destino al que estos tres enclaves están condenados.

La contribución de Mathieu Petithomme se centra en las trayectorias nacionalistas en el País Vasco y Cataluña y estudia las estrategias bastante divergentes actualmente adoptadas por lo unos y los otros con respecto a sus veleidades secesionistas. El artículo nos muestra cómo los vascos, acusados durante mucho tiempo de ser más separatistas que los catalanes, hoy quieren simplemente mantener los logros sociales y los avances económicos conseguidos. En cambio, buena parte de los catalanes, por su parte, dicen querer separarse de España, concibiendo el proyecto independentista como una esperanza y el final de las frustraciones. Una sociedad catalana que ya no adhiere o muy poco al discurso federalista, en la que el nacionalismo autonomista se ha debilitado fuertemente en el transcurso de las últimas décadas mientras que el sentimiento independentista se ha reforzado, gana cada vez más adeptos y parece estar más en sintonía con las expectativas de buena parte de la sociedad catalana actual.

Pero, ¿cómo se puede explicar esta inversión de roles? Esta es la cuestión central y eje de lectura principal de la contribución de Mathieu Petithomme. En ella, el autor propone algunas pistas explicativas de estas trayectorias nacionalistas divergentes al tiempo que insiste en el impacto de la crisis multiforme, económica, política y social a la vez, que golpeó duramente a España en 2008 pero cuyas consecuencias fueron diferentes en cada una de estas dos comunidades autónomas. Así, mientras que en Cataluña los partidarios de la independencia representan en la actualidad casi la mitad de la población, las encuestas de opinión realizadas en el País Vasco muestran que solo el $24 \%$ de los vascos dice estar a favor del proyecto independentista, el porcentaje más bajo desde hace décadas. Además, el País Vasco parece haber resistido mejor a los estragos de la crisis de 2008 (tasa de paro del 11,6\% a principios de 2012 frente a más del $22,8 \%$ a nivel nacional y un $20,9 \%$ en Cataluña; deuda pública del $7,2 \%$ muy por debajo de la deuda catalana que alcanzó el 16,9\% durante el mismo período), a diferencia de Cataluña, que fue una de las regiones más golpeadas por los efectos de la recesión y se convirtió por consiguiente en escenario de los primeros movimientos de contestación social por la crisis económica que rápidamente se extendieron por otras regiones. Una crisis que, como apunta Mathieu Petithomme, se ha convertido en Cataluña en una ventana de oportunidad política para hacer triunfar el proyecto secesionista catalán.

Los tres artículos siguientes abordan las situaciones de contacto lingüístico en los territorios peninsulares: País Vasco, Galicia y Cataluña, y dedican especial atención al aspecto microlingüístico del bilingüismo, a saber, de qué manera ha evolucionado el uso de las lenguas en la vida privada, así como las actitudes lingüísticas de los ciudadanos. Después de varias décadas de intensa actividad institucional para regular las modalidades del bilingüismo, a través de la política lingüística y la política educativa autónomicas, parece llegado el momento de hacer balance de los logros y los límites de estas iniciativas públicas, estudiando su repercusión en las prácticas y representaciones lingüísticas de los ciudadanos y en las políticas lingüísticas familiares. Como indicó Bierbach $^{42}$, podrían así diferenciarse dos tipos de tensiones entre lenguas, según el nivel de estudio en que nos situemos: en un nivel macrolingüístico, se enfrentan dos comunidades lingüísticas en lo que puede denominarse una lucha entre dos lenguas (o sus hablantes), donde la lengua A (dominante, exterior) se impone o intenta imponerse 
sobre la lengua $\mathrm{B}$, autóctona en un territorio. Desde la perspectiva microlingüística, el hablante resuelve cuestiones relacionadas con la selección de la lengua como lengua de identidad o según las situaciones, y en este ámbito puede hablarse de «conflicto» en tanto que necesidad de elegir no solo qué lengua, sino también qué modalidad de lengua (variedad normalizada o vernácula). Serían dos caras de la misma moneda, según Bierbach ${ }^{43}$, pues ambos interfieren: el enfrentamiento o lucha en el plano macrolingüístico puede condicionar las selecciones de los hablantes en su práctica bilingüe. A su vez, las instituciones reguladoras buscan cada vez más conocer e influenciar los usos lingüísticos de los individuos, conscientes de que toda intervención normalizadora macrolingüística se verá limitada en sus efectos si no consigue modificar los hábitos lingüísticos de los hablantes en su vida privada.

El trabajo de Sara Gómez Seibane aboga por un estudio del contacto vasco-español dentro de una perspectiva multidisciplinar, que tome en cuenta tanto el individuo como la comunidad de habla bilingües, junto a los sistemas lingüísticos en contacto. El artículo relaciona, en esta perspectiva, el contexto sociolingüístico en que conviven las dos lenguas así como los efectos del contacto a través de la interacción comunicativa. Para ello, se lleva a cabo una presentación histórica del contacto vasco-español y del marco jurídico que nace tras la dictadura franquista para favorecer el uso del euskera y regular la convivencia de ambas lenguas en las comunidades del País Vasco y Navarra. Se estudian asimismo las actitudes lingüísticas hacia el euskera por parte de los habitantes del País Vasco y de Navarra, destacándose la fuerte valoración positiva de esta lengua dentro de la sociedad vasca incluso en hablantes monolingües de español. Se analizan a continuación dos fenómenos del contacto: la convergencia en el orden de palabras y la alternancia códica, destacándose la importancia de los factores sociales para entender plenamente su funcionamiento.

Henrique Monteagudo, Anik Nandi y Xaquín Loredo se interrogan, por su parte, sobre la erosión de los procesos de transmisión lingüística intergeneracional en gallego y estudian el papel de los agentes sociales, en particular de las familias. Los autores analizan los perfiles sociolingüísticos de las familias gallegas para evaluar la eficacia de las políticas lingüísticas llevadas a cabo desde las instituciones y de las políticas lingüísticas familiares en el hogar. A pesar de la aparente «buena salud» del gallego en una sociedad con un alto porcentaje de bilingüismo activo, se observa un continuo descenso en el uso del gallego a favor del castellano. Se estudian por consiguiente en el artículo las estrategias de las familias mantenedoras y no mantenedoras (es decir, aquellas que se caracterizan por procesos de desgalleguización o regalleguización). Para ello, se escoge un método de estudio mixto, cuantitativo y cualitativo, aunando la perspectiva demolingüística y etnográfica. Se destaca en el trabajo cómo la toma en consideración de factores como la cronología o la distribución espacial de las familias estudiadas altera la perspectiva favorable en la transmisión del gallego pues revelan una tendencia lenta pero inevitable a la prevalencia de familias con lengua dominante castellana en Galicia. Como destacan los autores, a lo largo de los últimos 75 años, se observa un descenso continuo de las familias con lengua gallega dominante; a su vez, estas familias dominan en las áreas rurales, pero son minoritarias en las zonas urbanas. Por otra parte, las políticas lingüísticas familiares para promocionar el gallego entran en conflicto en las áreas urbanas con el prestigio social y simbólico del castellano, que incide en las propias selecciones lingüísticas de los niños en su socialización con sus pares. Además, los procesos de desgalleguización superan a los de regalleguización, si bien este perfil aumenta progresivamente a lo largo del tiempo. El detallado estudio de 
tres perfiles familiares diferentes (mantenedor en gallego, desgalleguizador y regalleguizador) pone de manifiesto la importancia de la célula familiar como agente de planificación lingüística y de transmisión intergeneracional, y se destaca su papel para revertir la tendencia a la desgalleguización, lenta pero imparable, a pesar de las políticas lingüísticas institucionales.

En su artículo, Mercè Pujol, después de recordar el marco jurídico de convivencia entre las lenguas cooficiales en Cataluña, basado en la Constitución española de 1978 y en la legislación de la Generalitat desde la II República española hasta la actualidad, pasa a interesarse por el nivel microlingüístico, es decir, el de los usos y actitudes lingüísticas de los individuos. Para ello, la autora toma en cuenta la presencia de población extranjera en Cataluña (un 15\% en 2019) y el alto número de lenguas habladas en el territorio (más de 300). En este contexto, el bilingüismo histórico de Cataluña, que se desarrolla especialmente en los siglos XIX y XX, con la progresiva entrada del castellano en amplios sectores de la sociedad catalana, ha pasado a convertirse en una situación de plurilingüismo, según la estudiosa. Las encuestas consultadas fueron llevadas a cabo por la Dirección de Política Lingüística de la Generalitat entre 2003 y 2018. Se desprenden de ellas los datos siguientes, destacados por la autora del artículo: un $13 \%$ de la población no tiene como lengua habitual ninguna de las lenguas cooficiales; el catalán es lengua habitual de un tercio de la población de forma sostenida pero retrocede su posición como lengua inicial (o materna) 㢄aunque con diferencias locales importantes间, lo cual puede obedecer a la llegada masiva de inmigración en los años de las encuestas; el uso del catalán como lengua habitual no está relacionada directamente con la mayor o menor presencia de población extranjera asentada en la región sino con el carácter urbano o rural de los territorios: las zonas rurales, con menor densidad de población, favorecen el empleo del catalán como lengua habitual. Estos datos vienen a sostener la hipótesis de la autora de que las situaciones plurilingües favorecen el mantenimiento de la lengua local, mientras que en las situaciones bilingües, la lengua dominada va perdiendo terreno indefectiblemente ante la lengua dominante. Por otro lado, en el hogar, el uso del castellano supera como lengua habitual al del catalán, lo que se interpreta como mantenimiento del castellano entre la emigración interna en Cataluña y sus descendientes. En las interacciones con los vecinos, se observa presencia de ambas lenguas cooficiales, así como un progresivo aumento de otras lenguas, mostrándose aquí el plurilingüismo del Principado. Destaca asimismo el alto porcentaje de individuos que declaran que en este ámbito solo usan el castellano (un 30\%), dato que sirve a la autora para negar la sustitución del castellano por el catalán, como se ha afirmado desde algunos sectores críticos con la normalización lingüística de Cataluña. Se presentan por último los usos lingüísticos referidos a la lengua de identificación. En sus conclusiones, Mercè Pujol pone de manifiesto la extrema movilidad de la situación lingüística en Cataluña, con el paso de una sociedad bilingüe a una sociedad multilingüe, en la que se ponen en marcha nuevas dinámicas de usos lingüísticos. El mantenimiento del catalán como lengua habitual en esta nueva tesitura debe acompañarse de medidas para favorecer su uso en el ámbito individual, y no solo institucional.

Por último, los artículos de Mónica Castillo Lluch y Marta López Izquierdo se interesan por el contacto lingüístico de las comunidades migrantes en la Europa francófona, en la línea de trabajos que ambas autoras desarrollan dentro de la Federación LAMIE 
(Federación internacional para el estudio de las lenguas de migrantes españoles en la Europa francófona) ${ }^{44}$.

El artículo de Mónica Castillo Lluch presenta el COLESfran (Corpus oral de la lengua española en la suiza francófona), elaborado desde 2013, para estudiar los procesos de integración lingüística de los inmigrantes hispanohablantes en este país, así como las formas de interferencia del francés que se detectan en el habla de los informantes. El artículo introduce la situación demográfica de los grupos estudiados en la Suiza francófona y la historia de su instalación en la región a partir de los años sesenta del pasado siglo. A continuación, se exponen los métodos y los objetivos del proyecto dirigido por la autora desde la Universidad de Lausana: los cuestionarios adaptados a cada generación, los protocolos y tecnologías usados para la transcripción, así como el objetivo pedagógico del proyecto, en el que participan activamente los estudiantes de español de la Universidad de Lausana. Se exponen finalmente las publicaciones que han nacido del proyecto y las colaboraciones internacionales en que el COLESfran está implicado.

Por su parte, Marta López Izquierdo se interesa en su artículo por los fenómenos del contacto de lenguas no estructurales, es decir, aquellos que afectan no solo a los sistemas lingüísticos propiamente dichos, sino que se manifiestan en las identidades lingüísticas de los grupos en contacto. Para ello, la autora estudia el proceso de integración lingüística de las poblaciones migrantes en la sociedad de acogida, y más concretamente, de las mujeres españolas inmigrantes en la Francia de los años 60, centrándose en los procesos de negociación identitaria que se ponen en marcha en los fenómenos de migración y que afectan tanto al inmigrante como a la sociedad de acogida. Se analiza así una selección de discursos elaborados por la sociedad francesa de los años 60 donde se ponen de manifiesto algunas de las representaciones sociales y estereotipos que circularon en esta época sobre la inmigración femenina, en torno a la figura de la «bonne» española (canciones populares, manuales de lengua). Estos discursos se contrastan con los de las propias inmigrantes, recogidos a través de encuestas sociológicas o testimonios cinematográficos, para comprender de qué manera interfieren las representaciones del grupo receptor con las del grupo migrante en la aculturación resultante y en qué medida esta es el producto de un proceso de acomodación doble: de los migrantes hacia la sociedad de acogida, y de esta hacia los migrantes.

\section{BIBLIOGRAFÍA}

Christine BIERBACH, «Cuatro idiomas para un Estado - ¿cuántos para una Región Autónoma? Observaciones acerca del debate sobre plurilingüismo y política lingüística en España», en Georg Bossong y Francisco Báez de Aguilar González (eds.), Identidades lingüísticas en la España autonómica: actas de las Jornadas Hispánicas 1997 de la Sociedad Suiza de estudios Hispánicos, Madrid/ Frankfurt, Iberoamericana/Vervuert, 2001, p. 17-37. 
Georg BossonG, «Prólogo», en Georg Bossong y Francisco Báez de Aguilar González (eds.), Identidades lingüísticas en la España autonómica: actas de las Jornadas Hispánicas 1997 de la Sociedad Suiza de estudios Hispánicos, Madrid/Frankfurt, Iberoamericana/Vervuert, 2001, p. 7-16, p. 10. Georg BossoNG, «Normes et conflits normatifs», en Hans Goebl et al. (eds.), Kontaktlinguistik / Contact Linguistics / Linguistique de contact, vol. 1, Berlin, De Gruyter Mouton, 1996, p. 609-624. Jean-Louis CALVET, La guerre des langues et les politiques linguistiques, Paris, Payot, 1987.

Mónica CASTILLO LLUCH, «Los discursos de los manuales de sociolingüística catalanes y la normalización: análisis desde los años 80 hasta la actualidad», en Mónica Castillo Lluch y Johannes Kabatek (eds.), Las lenguas de España. Política lingüística, sociología del lenguaje e ideología desde la Transición a la actualidad, Iberoamericana/Vervuert, Madrid/Frankfurt am Main, 2006, p. 223-239.

Mónica CASTILLO LLUCH y Johannes KABATEK, «Introducción », en Mónica Castillo Lluch y Johannes Kabatek (eds.), Las lenguas de España. Política lingüística, sociología del lenguaje e ideología desde la Transición a la actualidad, Iberoamericana/Vervuert, Madrid/Frankfurt am Main, 2006, p. 9-18.

Cornelius CASTORIADIS, L'institution imaginaire de la société, Paris, Le Seuil, 1975.

Réné DIRVEN y Martin PÜTZ, «Sprachkonflikt», en Hans GOEBL et al. (eds.), Kontaktlinguistik / Contact Linguistics / Linguistique de contact, vol. 1, Berlin, De Gruyter Mouton, 1996, p. 684-91.

Charles A. FERGUSON, «Diglossia», in Sociolinguistic Perspectives. Papers on Language in Society, 1959-1994, Thom Huebner (ed.), New York, Oxford, Oxford University Press, 1996.

Alicia FERNÁNDEZ GARCíA, Vivre ensemble. Conflit et cohabitation à Ceuta et Melilla, Paris, L'Harmattan, 2017.

Philippe GARDY et Robert LAFONT, « Diglossie comme conflict: l'exemple occitan ». Languages 61 (1981), p. 75-91.

Claude GEETS, « La peur de la différence », Pensée plurielle, vol.1, nº 5 (2003), p.7-16

Gobierno Vasco, VI Encuesta sociolingüística, 2016, <URL: https://www.euskadi.eus/gobiernovasco/politica-linguistica/>.

Claude HAGÈGE, L'enfant aux deux langues, Paris, Odile Jacob, 1996.

Einar HAUGEN, Language Conflict and Language Planning. The Case of Modern Norwegian, Cambridge, Harvard University Press, 1966.

Philippe HAMMAN, Sociologie des espaces-frontières, Strasbourg, PUS, 2013.

Grupo KOINÉ, «Per un veritable procés de normalització lingüística a la Catalunya independent», 2016 [consultado el 20/05/2021] <URL: http://llenguairepublica.cat/manifest/>.

Ángel LÓPEZ GARCÍA, El rumor de los desarraigados. Conflicto de lenguas en la Península Ibérica, Barcelona, Anagrama, 1985.

Ángel LóPEZ GARCíA, Repensar España desde sus lenguas, Barcelona, Viejo Topo, 2020.

Kenneth MACRAE, Conflict and compromise in multilingual societies. Switzerland, Waterloo, Wildrid Laurier University Press, 1983.

Albert MEMMI, Le racisme, Paris, Gallimard, 1982.

Henrique MONTEAGUDO, Xaquín LOREDO y Martín VÁZqUEZ, Lingua e sociedade en Galicia. Resumo de resultados 1992-2016, Real Academia Galega, A Coruña, 2018. 
Peter Hans NELDE, «Linguistic conflict», en Florian Coulmas (dir.), The Handbook of Sociolinguistics, Oxford \& Cambridge, Blackwell Publishing, 1998, 194-203.

Rafael Lluis DE NINYOLES, Cuatro idiomas para un Estado. El castellano y los conflictos lingüísticos en la España periférica, Madrid, Cambio 16, 1977.

Rafael Lluis DE NINYOLES, Conflicte lingüistic valencià, Valéncia, Eliseu Climent, 1969.

Ana Isabel PLANET CONTRERAS, Melilla y Ceuta. Espacios-frontera hispano-marroquies, Melilla, Ciudad autónoma de Melilla, 1998.

Claude RAFFESTIN, «Autour de la fonction sociale de la frontière», Espace et société, nº 70/71 (1992), p. $157-164$.

Manuel REGUEIRO TENREIRO, Modelo harmónico de relación lingüística. Estudio en Galicia, 3 Catorce Euro Ediciones, 1999.

Gilles VERBUNT, Penser et vivre l'interculturel, Lyon, Chroniques sociales, 2011.

Ulriel WEINREICH, Languages in Contact, New York, Linguistic Circle of New York, 1953.

Glyn WILLIAMS, Sociolinguistics. A Sociological Critique, London, Routledge, 1992.

\section{NOTAS}

1. Ulriel WEINREICH, Languages in Contact, New York, Linguistic Circle of New York, 1953.

2. «Le bilinguisme ne requiert pas de facultés cérébrales ni de processus mentaux spécifiques qui ne s'observeraient pas chez les unilingues», Claude HAGÈGE, L'enfant aux deux langues, Paris, Odile Jacob, 1996, p. 10.

3. «On a constaté depuis longemps que les bilingues possèdent généralement une malléabilité et une souplesse cognitives supérieures à celles des unilingues», Claude Hagège, Loc. cit.

4. Es muy abundante la bibliografía sociolingüística que vincula explícitamente el contacto de lenguas en sociedades bi/plurilingües al conflicto desde los años 60: Jean-Louis CALVET, La guerre des langues et les politiques linguistiques, Paris, Payot, 1987; Rafael Lluis DE NINYOLES, Cuatro idiomas para un Estado. El castellano y los conflictos lingüisticos en la España periférica, Madrid, Cambio 16, 1977; Ángel LÓPEZ GARCíA, El rumor de los desarraigados. Conflicto de lenguas en la Península Ibérica, Barcelona, Anagrama, 1985; Kenneth MACRAE, Conflict and compromise in multilingual societies. Switzerland, Waterloo, Wildrid Laurier University Press, 1983; Einar HAUGEN, Language Conflict and Language Planning. The Case of Modern Norwegian, Cambridge, Harvard University Press, 1966.

5. Charles A. FERGUSON, «Diglossia», en Sociolinguistic Perspectives. Papers on Language in Society, 1959-1994, Thom Huebner (ed.), New York, Oxford, Oxford University Press, 1996.

6. Joshua A. FISHMAN, «Bilingualism With and Without Diglossia; Diglossia With and Without Bilingualism», Journal of Social Issues 23, $\mathrm{n}^{\circ} 2$ (avril 1967), p. 29-38, p. 30, <URL: https://doi.org/ 10.1111/j.1540-4560.1967.tb00573.x.>.

7. FISHMAN, op. cit., p. 30.

8. "Without separate though complementary norms and values to establish and maintain functional separatism of the speech varieties, that language or variety which is fortunate enough to be associated with the predominant drift of social forces tends to displace the other(s)", FISHMAN, op. cit., p. 36.

9. Réné DIRVEN y Martin PÜTz, "Sprachkonflikt », en Hans Goebl et al. (eds.), Kontaktlinguistik / Contact Linguistics / Linguistique de contact, vol. 1, Berlin, De Gruyter Mouton, 1996, p. 684-91 ; Glyn WILLIAMS, Sociolinguistics. A Sociological Critique, London, Routledge, 1992. 
10. $C f$. para el ámbito del gallego en contacto con el español la propuesta de Manuel REGUEIRO TENREIRO, Modelo harmónico de relación lingüística. Estudio en Galicia, 3 Catorce Euro Ediciones, 1999.

11. Williams, op. cit., p. 105.

12. Peter Hans NELDE, «Linguistic conflict», en Florian Coulmas (dir.), The Handbook of Sociolinguistics, Oxford \& Cambridge, Blackwell Publishing, 1998, 194-203, p. 197. El propio Nelde indica, sin embargo: «The statement that there can be no language contact without language conflict [...] may appear exaggerated, but there is in the realm of the European languages at present no imaginable contact situation which cannot also be described as language conflict» (loc. cit.).

13. Cf. Philippe GARDY y Robert LAFONT, «Diglossie comme conflict : l'exemple occitan», Languages 61 (1981), p. 75-91, sobre la relación entre el occitano y el francés, y Rafael Lluis Ninyoles para el contacto catalán/español: «Ideològicament el bilingüisme 'explica' i alhora encobreix un mateix procès: el desplaçament d'un idioma par l'altre. S'ha observat sovint que, des del punt de vista psicológic, el bilingüisme és una situació inestable, de vegades purament transitòria. El conflicte es fa evident quan hi ha una contradicció entre l'acceptació d'una segona llengua i el refús d'aquelles situacions socials que l'han condicionada», en Conflicte lingüistic valencià, Valéncia, Eliseu Climent, 1969, p. 29-30.

14. NELDEN, op. cit., p. 197.

15. DIRVEN Y PUTZ, op. cit., p. 684.

16. Claude RAFFESTIN, «Autour de la fonction sociale de la frontière», Espace et société, no 70/71 (1992), p. 157-164.

17. Philippe HAMmAN, Sociologie des espaces-frontières, Strasbourg, PUS, 2013.

18. Alicia FERNÁNDEZ GARCíA, Vivre ensemble. Conflit et cohabitation à Ceuta et Melilla, Paris, L'Harmattan, 2017.

19. Gilles VERBUNT, Penser et vivre l'interculturel, Lyon, Chroniques sociales, 2011.

20. Albert MEMMI, Le racisme, Paris, Gallimard, 1982.

21. Claude GEETS, «La peur de la différence», Pensée plurielle, vol.1, no 5 (2003), p.7-16.

22. Ibid., p.16.

23. Ángel LóPEZ GARCíA, Repensar España desde sus lenguas, Barcelona, Viejo Topo, 2020, p. 29.

24. Ibid., p. 35-36.

25. La Ley de Normalización lingüística, 18 de abril de 1983 (https://www.google.com/url? sa=t\&rct=j\&q=\&esrc=s\&source=web\&cd=\&ved=2ahUKEwiq5JXgk8fwAhWQoBQKHexpD7IQFjADegQIDRAD\&url=https\%3A\%2F\%2Fwww.pa sitúa en un plano de igualdad la enseñanza del catalán y del castellano en la educación, mientras que el posterior Decreto-marco 75.1992, 9 de marzo de 1992, instituye al catalán como única lengua vehicular en la enseñanza, desde el preescolar hasta la secundaria.

26. Ley de Política Lingüística, 30 de diciembre de 1997.

27. Ley10/1982, de 24 de noviembre, básica de normalización del uso del Euskera, Boletín Oficial del Paîs Vasco.

28. Henrique MONTEAGUDO, Xaquín LOREDO y Martín VÁZqUEZ, Lingua e sociedade en Galicia. Resumo de resultados 1992-2016, Real Academia Galega, A Coruña, 2018, p. 6.

29. Si bien, como hemos visto, Fishman concebía este proceso como exento de conflicto, al desligar las lenguas de las condiciones sociales de los grupos que las hablan.

30. Op. cit., p. 52.

31. Antoni FERRANDO I FRANCÉS y Miquel NICOLÁs, Història de la llengua catalana Barcelona, Editorial UOC, 2011, p. 482.

32. Se trata de un grupo formado por lingüistas, sociolingüistas y filólogos que estudian el proceso de normalización lingüística para una futura República catalana independiente (cf. http://llenguairepublica.cat/qui-som/grup-koine/). 
33. Manifiesto «Per un veritable procés de normalització lingüística a la Catalunya independent», [consultado el 20/05/2021] <URL: http://llenguairepublica.cat/manifest/>.

34. Tampoco parece confirmarse la tendencia que observaba Mónica Castillo Lluch en su trabajo de 2006 («Los discursos de los manuales de sociolingüística catalanes y la normalización: análisis desde los años 80 hasta la actualidad», en Mónica Castillo Lluch y Johannes Kabatek (eds.), Las lenguas de España. Política lingüística, sociología del lenguaje e ideología desde la Transición a la actualidad, Iberoamericana/Vervuert, Madrid/Frankfurt am Main, 2006, p. 223-239.

35. Georg BossonG, «Prólogo», en Georg Bossong y Francisco Báez de Aguilar González, Identidades lingüísticas en la España autonómica: actas de las Jornadas Hispánicas 1997 de la Sociedad Suiza de estudios Hispánicos, Madrid/Frankfurt, Iberoamericana/Vervuert, 2001, p. 7-16, p. 10.

36. $C f$. sobre la deseable neutralidad de la sociolingüística los comentarios de Castillo Lluch y Kabatek en la introducción del volumen colectivo Las lenguas de España. Política lingüística, sociología del lenguaje e ideología desde la Transición a la actualidad, Iberoamericana/Vervuert, Madrid/Frankfurt am Main, 2006, p. 9-18, especialmente p. 15. Cabe preguntarse si la normalización lingüística, proceso fundamentalmente político (cf. Georg BossonG, «Normes et conflits normatifs», en Hans Goebl et al. (eds.), Kontaktlinguistik / Contact Linguistics / Linguistique de contact, vol. 1, Berlin, De Gruyter Mouton, 1996, p. 609-624, p. 611), puede concebirse fuera de una órbita ideológica y si la neutralidad no sería dejar que las comunidades bilingües o plurilingües regulen «naturalmente» (término que también necesitaría explicitación), es decir, sin intervención política ni legislativa, la convivencia entre sus lenguas. El sociolingüista como observador-descriptor, ¿debe abstenerse de recomendar y promover ciertas actuaciones públicas, en favor de una u otra regulación lingüística? ¿puede intervenir, como asesor o instigador de la normalización lingüística, desde una posición neutral? Nos parece que estas preguntas merecerían un desarrollo mayor del que podemos dedicarles aquí.

37. Gobierno Vasco, VI Encuesta sociolingüística, 2016 <URL: <https://www.euskadi.eus/gobiernovasco/politica-linguistica/>.

38. Idescat (Institut d'Estadística de Catalunya), https://www.idescat.cat/indicadors/? $\mathrm{id}=$ anuals\&n=10367\&tema=cultu\&t=201300 y $\quad$ https://www.idescat.cat/indicadors/? id=anuals\&n=10367\&tema=cultu\&t=201800.

39. Porcentaje de personas que declaran dominar la competencia hablada en gallego. El porcentaje es más bajo si se considera la competencia escrita, aunque también progresa en el mismo período, y de manera más importante: 27\% en 1992 - 58\% 2016. Fuente: MONTEAGUDO, LOREDO Y VÁZQUEZ, op. cit., p. 8.

40. Cornelius CASTORIADIS, L'institution imaginaire de la société, Paris, Le Seuil, 1975.

41. Ana Isabel PLANET CONTRERAS, Melilla y Ceuta. Espacios-frontera hispano-marroquies, Melilla, Ciudad autónoma de Melilla, 1998.

42. Christine BIERBACH, «Cuatro idiomas para un Estado - ¿cuántos para una Región Autónoma? Observaciones acerca del debate sobre plurilingüismo y política lingüística en España», en Georg Bossong y Francisco Báez de Aguilar González (eds.), Identidades lingüísticas en la España autonómica: actas de las Jornadas Hispánicas 1997 de la Sociedad Suiza de estudios Hispánicos, Madrid/ Frankfurt, Iberoamericana/Vervuert, 2001, p. 17-37.

43. Christine BIERBACH, op. cit., p. 25.

44. $C f$. https://etudes-romanes.univ-paris8.fr/?Federation-LAMIE. 


\section{AUTORES}

ALICIA FERNÁNDEZ GARCÍA

Université Paris 8

MARTA LÓPEZ IZQUIERDO

Université Paris 8 